\title{
Lupus bulloso como debut de lupus eritematoso sistémico. Reporte de caso
}

\author{
Lupus bullosus as the debut of systemic lupus erythematosus. Case report \\ María F. Basurto-Pérez*, María D.R. Ramírez-Galindo y Luisa F. Carbonell-Montes \\ Servicio de Urgencias de Adultos, Hospital General 450, Secretaría de Salud, Durango, México
}

\section{Introducción}

El lupus eritematoso sistémico (LES) es una enfermedad autoinmunitaria de curso crónico y causa desconocida, con numerosas manifestaciones clínicas y multisistémicas. La prevalencia en la población general es de 4 a 250 casos por cada 100,000 habitantes. En México, la prevalencia es de 88 casos por 100,000 habitantes, con predominio en mujeres entre los 15 y 65 años de edad. El lupus bulloso es una presentación infrecuente del LES y se caracteriza por el desarrollo de bullas de diferentes tamaños, generalmente distribuidas sobre zonas de la piel expuestas a la luz. Se considera una enfermedad rara, con una prevalencia de 0.2 por cada 10 millones de habitantes, y representa menos del $5 \%$ de las manifestaciones cutáneas del $\operatorname{LES}^{1,2}$.

\section{Presentación del caso}

Mujer de 15 años, sin antecedentes de enfermedades crónicas degenerativas. Inició el cuadro clínico el día 28 de octubre de 2021 con ataque al estado general, odinofagia y mialgias. Dos días después presenta cefalea holocraneana, de intensidad 8/10 en la escala visual analógica, de tipo punzante, dolor intenso en el ojo izquierdo con disminución de la agudeza visual y lesiones equimóticas en los miembros inferiores. Es derivada a urgencias del Hospital General 450, donde ingresa con presión arterial de $90 / 50 \mathrm{mmHg}$, frecuencia cardiaca de 102 latidos por minuto, frecuencia respiratoria de 22 respiraciones por minuto, temperatura de $36.3^{\circ} \mathrm{C}$ y saturación de oxígeno del $92 \%$, con Glasgow de 14 puntos, desorientada, sin datos de irritación meníngea, con midriasis bilateral de $4 \mathrm{~mm}$, palidez de tegumentos, cuello sin adenopatías, movimientos de ampliación y amplexación simétricos, sin datos de dificultad respiratoria, abdomen sin visceromegalias y extremidades inferiores con múltiples lesiones equimóticas. Los laboratorios (Tabla 1) muestran leucocitosis de $25 \times 10^{3}$, neutrófilos $89 \%$, hemoglobina $11.3 \mathrm{mg} / \mathrm{dl}$, lactato 5.1 y proteína $C$ reactiva 402 .

\section{Abordaje}

Por sospecha de meningitis bacteriana se realiza punción lumbar, que reporta líquido xantocrómico, turbio, leucocitos de 1430 , polimorfonucleares $66 \%$, glucosa 30 y proteínas 60 , sin desarrollo en los cultivos bacteriológicos, quedando con diagnóstico de meningitis aséptica, además de leucocitosis y proteína $C$ reactiva elevada (Tabla 1). Transcurridas 24 horas

\section{Correspondencia:}

*María F. Basurto-Pérez

E-mail: maria_fe333@hotmail.com
Disponible en internet: 07-03-2022 Rev Educ Investig Emer. 2022;4(Supl 1):74-77 www.medicinadeemergencias.com

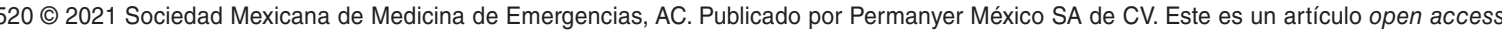
bajo la licencia CC BY-NC-ND (http://creativecommons.org/licenses/by-nc-nd/4.0/). 
Tabla 1. Laboratorios desde el ingreso hasta el egreso. Obsérvense la marcada leucocitosis de ingreso, con elevación de la proteína C reactiva, los valores del líquido cefalorraquídeo con datos de meningitis bacteriana, el perfil tiroideo normal y la prueba de reacción en cadena de la polimerasa para SARS-CoV-2 negativa

\begin{tabular}{|c|c|c|c|c|}
\hline $31 / 10 / 2021$ & $01 / 11 / 2021$ & 03/11/2021 & $05 / 11 / 2021$ & $12 / 11 / 2021$ \\
\hline Leucocitos $23 \times 10^{3}$ & Leucocitos $22 \times 10^{3}$ & $\begin{array}{l}\text { Punción lumbar: color } \\
\text { xantocrómico, turbio, leucocitos } \\
1430 \text {, polimorfonucleares } 66 \% \text {, } \\
\text { glucosa } 97 \text {, proteínas } 60\end{array}$ & $\begin{array}{l}\text { Perfil tiroideo: } \\
\text { T4: } 0.91 \mathrm{~g} / \mathrm{dl} \\
\text { T3: } 0.80 \mathrm{ng} / \mathrm{dl} \\
\text { TSH: } 0.44 \mathrm{~g} / \mathrm{dl}\end{array}$ & ANA positivo \\
\hline \multirow[t]{5}{*}{ Neutrófilos $89 \%$} & Neutrófilos $92.9 \%$ & & $\begin{array}{l}\text { Procalcitonina } 0.89 \mathrm{ng} / \\
\mathrm{ml}\end{array}$ & \\
\hline & $\mathrm{P} 2.4 \mathrm{mmol} / \mathrm{lt}$ & Proteína $C$ reactiva $408 \mathrm{~g} / \mathrm{dl}$ & $\begin{array}{l}\text { PCR para SARS-CoV-2: } \\
\text { negativa }\end{array}$ & \\
\hline & DD $1140 \mathrm{gr} / \mathrm{dl}$ & Procalcitonina $4.99 \mathrm{ng} / \mathrm{ml}$ & & \\
\hline & Proteína C reactiva $402 \mathrm{~g} / \mathrm{dl}$ & & & \\
\hline & Perfil toxicológico negativo & & & \\
\hline
\end{tabular}

ANA: anticuerpos antinucleares; DD: dimero d; P: fosforo; PCR: reacción en cadena de la polimerasa; T3: triyodotironina; T4: tiroxina; TSH: hormona estimulante de la tiroides.

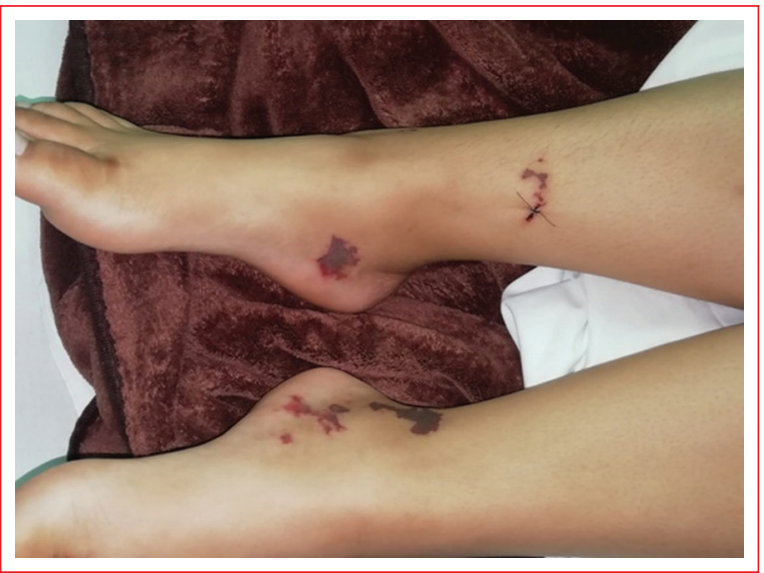

Figura 1. Lesiones equimóticas en las extremidades inferiores, no dolorosas ni pruriginosas, de predominio en región del tobillo, cara interna y cara anterior de la pierna; de esta última se tomó biopsia, con reporte de lupus bulloso.

persiste con cefalea, dolor en el ojo izquierdo y pérdida de la agudeza visual. La resonancia magnética craneal revela puntos de gliosis, ganglios reactivos y quiste en la fisura coroidea, sin compromiso oftálmico en la órbita ni los tejidos blandos. Se indica por parte de oftalmología antibiótico y esteroide tópico. Ante la presencia de las lesiones equimóticas con aparición de múltiples bullas de $1 \mathrm{~cm}$ (Fig. 1) y la meningitis aséptica se sospecha LES y se inicia manejo con bolos de metilprednisolona. Se solicitó determinación de anticuerpos antinucleares (ANA) y anticitoplasma del neutrófilo

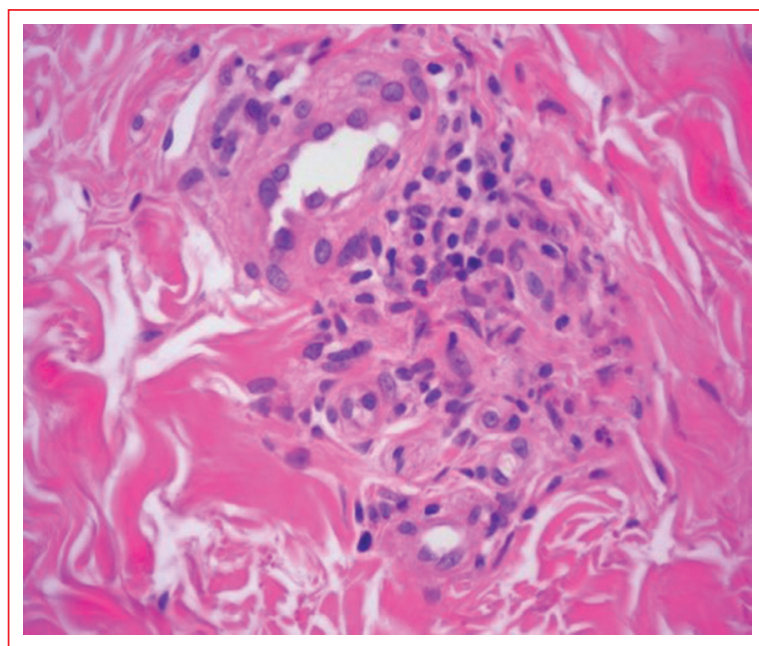

Figura 2. Tinción de hematoxilina-eosina que muestra infiltración de neutrófilos y linfocitos.

(ANCA), y complemento. El día 5 de noviembre de 2021 se realizó biopsia de piel de una de las lesiones esquimóticas, que 6 días después se reporta como lupus bulloso (Fig. 2).

\section{Diagnósticos diferenciales}

El lupus cutáneo ampolloso obliga a establecer el diagnóstico diferencial con penfigoide bulloso, dermatitis herpetiforme y epidermólisis bullosa adquirida, las cuales pueden ser simuladoras. Por lo general, estas 
enfermedades se diferencian del lupus por sus cambios histopatológicos característicos en la membrana basal y los anticuerpos circulantes en suero ${ }^{3}$.

\section{Desenlace y seguimiento}

Se egresa a su domicilio el 12 de noviembre con reporte de ANA positivos, en tratamiento por reumatología y oftalmología.

\section{Discusión}

El lupus bulloso es una manifestación cutánea del LES agrupada dentro de las que se consideran subagudas $^{2}$. Se caracteriza por una erupción con ampollas y vesículas tensas con un fondo eritematoso; las áreas expuestas al sol son las más afectadas, aunque las lesiones también se pueden presentar en zonas no expuestas, siendo el tronco superior, el cuello, las regiones supraclaviculares, los pliegues axilares y la parte proximal de las extremidades las áreas de predilección. Las lesiones pueden surgir sobre una piel eritematosa o normal; son tensas, con líquido claro o hemorrágico, y ocasionalmente se rompen dejando erosiones, costras y cambios pigmentarios (máculas hipopigmentadas o hiperpigmentadas). Suelen ser múltiples, se expanden rápidamente hacia la periferia y se unen formando figuras alargadas e irregulares ${ }^{4}$.

La fisiopatología del desarrollo de las bullas se explica por depósitos de anticuerpos contra la unión dermoepidérmica del colágeno tipo VII; este colágeno es vital como fibrilla de anclaje que une la epidermis a la dermis. Los autoanticuerpos circulantes se dirigen contra el dominio no colágeno tipo 1 y 2 del colágeno tipo VII en la zona de la membrana basal ${ }^{4}$, lo que da como resultado una adhesión dérmica-membrana basal debilitada, que se manifiesta como ampollas subepidérmicas $^{5}$. Histopatológicamente, las ampollas subepidérmicas muestran una densa infiltración neutrofílica en la dermis superior concentrada en la punta papilar, con la asociación de polvo nuclear y fibrina; como característica distintiva, presentan grandes depósitos de mucina en la dermis reticular ${ }^{6}$. La inmunofluorescencia muestra depósitos lineales de inmunoglobulinas (Ig) A, $G$ y $M$, y en menor medida en el C3 en la membrana basal ${ }^{4}$.

En 1983, Camisa y Sharma ${ }^{7}$ propusieron los siguientes criterios diagnósticos:

- Diagnóstico de LES basado en los criterios del American College of Rheumatology.
- Vesículas y ampollas que no se limitan a la piel expuesta al sol.

- Histopatología compatible con dermatitis herpetiforme.

- Inmmunofluorescencia indirecta negativa para anticuerpos circulantes contra la zona de la membrana basal, utilizando la piel separada como sustrato.

- Inmunofluorescencia directa que revela $\lg G$ o $\lg M$, y a menudo IgA, en la zona de la membrana basal.

Los corticoides, como la prednisona, junto con la terapia inmunomoduladora, son el tratamiento estándar. La dapsona es eficaz a dosis de 25-50mg por dia para el cese en la formacion de nuevas ampollas en un lapso de 1-2 dias luego de iniciado el tratamiento y se pueden resolver completamente las lesiones entre los 7 a 10 dias $^{4}$. Otros tratamientos son el micofenolato de mofetilo y los inhibidores de linfocitos $\mathrm{CD}_{2}{ }^{2}$. En los casos refractarios se requiere manejo con terapia biológica $^{5}$.

\section{Conclusiones}

El lupus bulloso es una manifestación cutánea del LES, que puede ser su forma de presentación inicial o aparecer como complicación de este. Su diagnóstico exige una alta sospecha clínica y su manejo es multidisciplinario. Las causas de muerte más frecuentes son las infecciones, los eventos cerebrovasculares, la nefropatía y las lesiones neurológicas. La supervivencia ha mejorado con las nuevas técnicas diagnósticas, el uso de nuevas terapias y la formación de especialistas con un alto nivel científico.

\section{Agradecimientos}

A todo el personal medico, de enfermeria y patologia del HG 450, por su disposicion, entrega y pasion en la atencion de los pacientes que ingresan a la sala de urgencias.

\section{Financiamiento}

Los recursos para este estudio provienen de los mismos autores.

\section{Conflicto de intereses}

Los autores no reportan ningún conflicto de intereses. 


\section{Responsabilidades éticas}

Protección de personas y animales. Los autores declaran que para esta investigación no se han realizado experimentos en seres humanos ni en animales.

Confidencialidad de los datos. Los autores declaran que han seguido los protocolos de su centro de trabajo sobre la publicación de datos de pacientes.

Derecho a la privacidad y consentimiento informado. Los autores han obtenido el consentimiento informado de los pacientes y/o sujetos referidos en el artículo. Este documento obra en poder del autor de correspondencia.

\section{Bibliografía}

1. Gharib K. Childhood bullous systemic lupus erythematosus: unusual prognosis. Egyptian Journal of Dermatology and Venereology. 2020;41:16-21.

2. Guillén Astete CA, Lucica Boteanu A, Gámir Gámir ML, Sánchez Neila N. Respuesta exitosa del manejo con dapsona de un caso de lupus bulloso en un paciente con lupus eritematoso sistémico juvenil. Acta Reumatológica. 2015;2:62-6.

3. Escorcia Charris EJ, Carbono Camargo J, Salas Siado J, Coronell Buzon L. Lupus ampolloso: un verdadero reto diagnóstico y terapéutico. Biociencias. 2018;12:31-5.

4. Contestable JJ, Edhegard KD, Meyerle JH. Bullous systemic lupus erythematosus: a review and update to diagnosis and treatment. Am J Clin Dermatol. 2014;15:517-24.

5. Tincopa M, Puttgen KB, Sule S, Cohen BA, Gerstenblith MR. Bullous lupus: an unusual initial presentation of systemic lupus erythematosus in an adolescent girl. Pediatr Dermatol. 2010;27:373-6.

6. de Risi-Pugliese T, AubartFC, Haroche J, MogueletP, Grootenboer-MignotS, Mathian A, et al. Clinical, histological, immunological presentations and outcomes of bullous systemic lupus erythematosus: 10 new cases and a literature review of 118 cases. Semin Arthritis Rheum. 2018;48:83-9.

7. Camisa C, Sharma HM. Vesiculobullous systemic lupus erythematosus: report of two cases and a review of the literature. J Am Acad Dermatol. 1983:9:924-33. 